\title{
Studies on the removal of copper ions from industrial effluent by Azadirachta indica powder
}

\author{
Suhair Saif AI Moharbi ${ }^{1} \cdot$ M. Geetha Devi ${ }^{1} \cdot$ B. M. Sangeetha ${ }^{1} \cdot$ Shah Jahan ${ }^{1}$
}

Received: 17 December 2018 / Accepted: 18 November 2019 / Published online: 3 December 2019

(c) The Author(s) 2019

\begin{abstract}
Rapid industrialization, urbanization and population growth have resulted in air, water and land pollution. Water pollution is a major concern across the globe. Discharge of huge amount of industrial wastewater adversely affects the human and environment. Heavy metal pollution is considered to be one of the serious environmental problems today. Due to strict environmental regulations in the country, it is required to bring down the pollution level to a permissible limit. The present study assessed the capability of Azadirachta indica (neem leaf) powder as a natural adsorbent in the removal of copper ions from aqueous solutions. The characterization of the adsorbent was performed using X-ray diffraction, scanning electron microscopy and Fourier-transform infrared spectroscopy. Series of batch experimental studies were carried out by changing the solution $\mathrm{pH}$, stirring time, adsorbent dosage and stirring speed in the removal of copper from aqueous solution using A. indica as biosorbent. The experimental result shows that the percentage removal of copper was highest at the following optimized conditions: $\mathrm{pH} 7.0$, stirring time $60 \mathrm{~min}$ and biosorbent dosage of $1.0 \mathrm{~g}$ and at $125 \mathrm{RPM}$ speed. The studies indicate that $A$. indica is considered to be a promising type of biomass for the removal of copper ions from aqueous solutions.
\end{abstract}

Keywords Atomic absorption spectrophotometer $\cdot$ Azadirachta indica $\cdot$ Biosorbent $\cdot$ Fourier-transform infrared spectroscopy $\cdot$ Neem leaves $\cdot$ Scanning electron microscopy $\cdot$ X-ray diffraction

\section{Introduction}

Chemical industries consume huge quantity of water during its physical, chemical and biological processing stages and discharge significant amount of wastewater (Manjunatha and Vagish 2016). The discharge of heavy metals from industrial operations is more hazardous due to the presence of copper, chromium, zinc, nickel and cadmium (Basha et al. 2008). Larger concentrations of copper in the effluent stream cause serious health problems in brain, kidney and anemia. Copper consumption at high dosages leads to serious toxicological concerns since it could be deposited in the brain, skin, liver and kidney (Malik et al. 2014). Chemical precipitation and electrochemical treatment methods are less efficient and also generate a large quantity of sludge, which is difficult to treat (Ceribasi and Yetis 2001). Higher concentrations of

M. Geetha Devi

geethadevi@nu.edu.om; gdmdevi@gmail.com

1 Department of Mechanical and Industrial Engineering, National University of Science \& Technology - College of Engineering, Seeb, Oman copper cause vomiting, cramps, convulsions or even death (Paulino et al. 2006). As per the national and international standards, the permissible limit for the discharge of copper is $0.25 \mathrm{mg} / \mathrm{L}$. Most commonly used adsorbents are activated carbon, silica, alumina, etc. which are expensive, non-degradable and toxic (Zhonghua et al. 2003; Kumar et al. 2007; $\mathrm{Li}$ et al. 2009). This has inspired researchers to think about cheap and natural adsorbents such as biomass, tamarind seeds, pomegranate husk, rice husk and fly ash (Malairajan et al. 2007; Suresh and Babu 2006; El Nemr 2007; Puziah and Chin 2007).

Removal of heavy metals from industrial wastewater is becoming more expensive due to non-biodegradability, toxicity, carcinogenic and extremely high cost. Though adsorption of heavy metals from industrial wastewater using activated carbon is effective as it removes $99 \%$ of metal ions, the cost of production is extremely high and the adsorbents could not be regenerated. Biosorption techniques are considered as a cost-effective and environmental friendly process for the removal of metals from industrial wastewater and also for the recovery of precious metals from effluent. Different functional groups present in the biomaterials make 
it possible for them to attach metal ions on the surface for wastewater treatment applications (Volesky 2001).

Biosorption is an ideal choice in the metal removal process due to its low cost, better metal-binding capacity, high efficiency in dilute effluents and environmental friendly nature (Volesky and Holan 1995). The biosorption mechanisms include extracellular and intracellular bonds, as well as complex interactions that depend on the type of metal and the biosorbent structure. Removal of metal ions by biosorption process using biological materials is considered as a potentially viable sorbent for heavy metal removal (Davis et al. 2003).

The choice of a prospective biomass derived from natural materials in the biosorption application is a real challenge to researchers and environmental engineers. The biosorption efficiency depends on the availability of active sites on the surface of biomass and their chemical structure (Arshad et al. 2008). Most common types of biosorbents for the removal of heavy metals are algae, agricultural waste, bacteria and fungi (Vijayaraghavan and Yun 2008). Neem leaf contains $22.9 \%$ carbohydrates, $6.2 \%$ fiber, $7.1 \%$ protein and the rest is moisture (Ang et al. 2012).

A series of batch studies have been carried out by various researchers utilizing raw Azadirachta indica (neem) leaf powder, as a low-cost natural adsorbent to remove chromium(VI) and copper with considerable removal efficiency. The parameters varied in the study are the agitation time, adsorbent size and dosage, initial chromium concentration, volume of aqueous solution and $\mathrm{pH}$ of the aqueous solution (Islamuddin et al. 2016; Sulaiman and Garba 2014). The experimental outcomes obtained from the study indicate that raw neem leaf powder is a promising biosorbent for the economical removal of $\mathrm{Cr}$ and $\mathrm{Cu}$ (II) ions from aqueous solutions. Another study by Malik et al. (2014) focused on the simultaneous removal of copper and zinc from water using powdered neem leaves by batch adsorption process. The optimum $\mathrm{pH}$ for the effective removal of copper and zinc was found to be 5.0 and 4.0, respectively. The results indicated that the uptake capacity of zinc was better than that of copper. Hence, neem leaf powder was suggested to be an excellent biomaterial for accumulating zinc from aqueous solutions (Malik et al. 2014). The batch adsorption of $\mathrm{Cu}(\mathrm{II})$ ions from synthetic solution of copper was investigated by Sethu et al. (2009) using neem leaf powder by varying the agitation time and adsorbent dosage. The maximum Cu removal efficiency was $40 \%$ for $120 \mathrm{~min}$ stirring time with an optimum $\mathrm{pH}$ of 4.5-5.5. The results obtained from the batch adsorption study show that neem leaf powder is suitable for removing copper from wastewater, and it was suggested that further studies are needed to improve the efficiency by changing other parameters such as the concentration of copper ion, $\mathrm{pH}$ of the solution and temperature.
Raw neem leaf powder of size around $90 \mu \mathrm{m}$ was used as biosorbent for the removal of $\mathrm{Cu}$ (II) ions from aqueous solutions by varying the dosage. The optimum conditions for the efficient removal of $\mathrm{Cu}(\mathrm{II})$ were dosage of $1 \mathrm{~g} / \mathrm{L}$, $\mathrm{pH} 3.0$, temperature $303 \mathrm{~K}$, and $74.08 \% \mathrm{Cu}$ removal efficiency was achieved. However, the removal efficiency may be enhanced by immobilizing the neem leaf powder on a stable surface. It was suggested that the suggested technology may be applied in the removal of other types of heavy metals from wastewater (Rasheed et al. 2014). Low-cost adsorbent was prepared from neem leaves by chemical activation, and the resulting activated carbon was utilized for the removal of color (Pandhare et al. 2013).

The maximum removal efficiency at optimized conditions was found to be $80 \%$. The experimental outcomes indicated the tremendous potential of neem leaves as a low-cost adsorbent for wastewater treatment applications.

Batch adsorption of chromium(VI) from aqueous solution using neem leaves ( $A$. Indica) was performed by varying the adsorbent dosage, $\mathrm{pH}$, agitation time, temperature and concentrations of the metal. The maximum $\mathrm{Cr}(\mathrm{VI})$ removal occurred in $300 \mathrm{~min}$ from a solution of concentration of $14.1 \mathrm{mg} / \mathrm{dm}^{3}$ and at $300 \mathrm{~K}$ for an optimum range of 4.5-7.5. The suitability of the adsorbent was assessed using Langmuir and Freundlich isotherms (Sharma and Bhattacharyya 2004). The performance of neem leaf powder for the removal of copper from aqueous solution was carried out in batch and dynamic modes at optimum $\mathrm{pH}$ of 5.0. The experimental data were fitted using Freundlich and Langmuir adsorption models, and the adsorption of copper ion onto neem leaf was endothermic (Novie Febriana et al. 2010). The adsorbents derived from $A$. Indica (neem) leaves have been utilized for the effective removal of heavy metal ions from wastewater (Pournima and Shrikant 2018). The adsorbent surface was chemically modified using various modification methods for improved adsorption. Assessment of adsorption properties of neem leaves wastes for the removal of Congo red and methyl orange was investigated by Muhammad et al. (2015). The experimental outcome shows that neem leaves biomass could be a cost-effective material for the efficient uptake of metal ions present in aqueous solutions.

The above-listed literature shows that most of the biosorption processes for heavy metal removal are carried out using raw A. Indica powder. So far, no major study has been carried out using surface-modified A. Indica powder for adsorption of copper ions.

The objective of the current research was to assess the efficiency of activated A. Indica powder in the removal of copper from wastewater in a cost-effective and environmental friendly way. The neem leaves were collected from the coastal regions in the Sultanate of Oman. The biosorption experiment was performed in the College of Engineering Laboratory during March-May 2018. 


\section{Materials and methods}

\section{Materials}

Azadirachta indica powder was prepared by drying a known amount of neem leaves under shade for 3 days followed by grinding and sieving to get fine powder of desired size (less than $40 \mu \mathrm{m}$ ). Neem leaf powder was washed to remove moisture and dried for $30 \mathrm{~min}$. The dried sample was mixed with $\mathrm{H}_{3} \mathrm{PO}_{4}$ in a silica crucible and heated in a furnace at $260{ }^{\circ} \mathrm{C}$ for $20 \mathrm{~min}$. The resulting sample was cooled to room temperature and washed with hot water several times to remove free acid and moisture, followed by drying in an oven for $25 \mathrm{~min}$ to form a black colored adsorbent powder for further use.

Stock solutions of copper were prepared by dissolving stoichiometric amount of $\mathrm{CuSO}_{4} 5 \mathrm{H}_{2} \mathrm{O}$ in Millipore water. This stock solution was diluted to the desired concentration for further experiments. All reagents were procured from Sigma-Aldrich, India.

The surface characterization of the sample before and after biosorption was carried out using field emission scanning electron microscope (SEM JEOL JSM-7600F), structural characteristics by X-ray diffractometer (Rigaku, and Mini Flex 600), and surface functional groups are determined using Fourier-transform infrared spectroscopy (FTIR, Frontier, PerkinElmer). Concentration of copper ion was measured using atomic absorption spectrophotometer (AAS, PerkinElmer). All characterizations were carried out at room temperature.

The batch experimental studies were performed by mixing desired amount of biosorbent into a series of conical flasks containing $100 \mathrm{ml}$ of solutions at a specified metal concentration. The mixture was agitated in a magnetic stirrer setup for $2 \mathrm{~h}$. The resulting mixture was centrifuged at $6000 \mathrm{RPM}$ for $10 \mathrm{~min}$, and the concentration of the supernatant was measured using atomic absorption spectrophotometer (AAS). In order to keep consistency, each experiment was repeated three times and the average of three values was reported as final value. The error percentage obtained in all experiment was less than $5 \%$.

\section{Batch adsorption studies}

The batch adsorption studies were performed by mixing $100 \mathrm{ml}$ of the copper sulfate solution with $0.5 \mathrm{~g}$ of $A$. Indica powder and agitated for $2 \mathrm{~h}$ at room temperature. The resulting mixture was centrifuged at 6000 RPM for $10 \mathrm{~min}$. The amount of copper adsorbed was measured using atomic absorption spectrophotometer. The effectiveness of copper adsorption from aqueous solution was studied by varying the experimental conditions such as solution $\mathrm{pH}$, stirring time, stirring speed, concentration of solution and dosage of biosorbent.

The percentage removal of copper was estimated using the following equation:

$\%$ Removal of copper $=\frac{C_{\mathrm{i}}-C_{0}}{C_{\mathrm{i}}} \times 100$, where $C_{\mathrm{i}}$ is the initial concentration and $C_{0}$ is the final concentration in $\mathrm{mg} / \mathrm{L}$.

\section{Effect of variation of parameters in the removal of copper}

\section{Influence of solution $\mathrm{pH}$}

The influence of solution $\mathrm{pH}$ on copper removal was studied by varying the effluent solution $\mathrm{pH}$ from 2.0 to 10.0. For this, a synthetic solution of copper sulfate of concentration $100 \mathrm{mg} / \mathrm{L}$ was prepared and $\mathrm{pH}$ of the solution was varied from acidic to alkaline range. The adsorbent dosage was $0.5 \mathrm{~g}$, and stirring time was $60 \mathrm{~min}$. The solution concentration was analyzed using AAS.

\section{Influence of stirring time}

Stirring time is one of the important parameters to be considered in the removal of pollutants from wastewater. The influence of stirring time in the removal of copper was studied by changing the stirring time from 30 to $120 \mathrm{~min}$. The $\mathrm{pH}$ of the solution was kept constant for all samples.

\section{Influence of stirring speed}

The influence of stirring speed with percentage removal of copper was studied by changing the stirring speed from 25 to $150 \mathrm{RPM}$ at optimized values of $\mathrm{pH}$ and contact time.

\section{Influence of biosorbent dosage}

The influence of dosage of biosorbent on the removal of copper was performed by varying the dosage of $A$. Indica powder from 0.1 to $1.5 \mathrm{~g}$, keeping all other experimental parameters optimum.

\section{Influence of concentration of effluent solution}

Concentration of the effluent plays an important role in metal removal process. The influence of effluent concentration on the removal of copper was performed by varying the concentration of effluent from 0 to $100 \mathrm{ppm}$, keeping all other experimental parameters optimum. 


\section{Results and discussion}

\section{Preparation and characterization of Azadirachta indica powder}

The A. Indica powder was prepared by drying a known amount of neem leaves under shade followed by grinding and sieving to get the powder of required size. Surface characterization of biosorbent was carried out using scanning electron microscopy (SEM), Fourier-transform infrared spectroscopy (FTIR) and energy-dispersive X-ray spectroscopy (EDX). FTIR spectroscopy technique was used to determine the functional groups available in $A$. Indica powder. Figure 1 illustrates the scanning electron microscopy image of the A. Indica powder at a magnification of $230 \mathrm{X}$ and an excitation voltage of $15.0 \mathrm{kV}$. It was observed from Fig. 1 that the powder does not possess any regular shape and size. The functional groups present on the surface of neem leaf powder before and after adsorption were analyzed using FTIR.

The phase identification of the A. Indica powder was analyzed using an X-ray diffractometer. Figure 2 indicates the XRD spectra of $A$. Indica powder before treatment.

The functional groups present in the biosorbent were identified by FTIR spectroscopy as shown in Fig. 3. FTIR analysis indicated the actual bond stretching and functional groups present on the surface of sample. The spectral range was captured between wave number $500-4500 \mathrm{~cm}^{-1}$. Figure 3 shows the details of FTIR spectra of the activated $A$. Indica sample. Table 1 illustrates the types of functional groups identified in the biosorbent sample before adsorption process.

The FTIR spectra shown in Fig. 3 illustrate the existence of niacin, proline, glutamic acid, aspartic acid, glutamine, tyrosine and alanine in A. Indica contributed to the
Fig. 1 SEM micrograph of activated Azadirachta indica powder before adsorption at a magnification of $\times 230$ and at $15 \mathrm{kV}$
Fig. 2 XRD pattern of Azadirachta indica before treatment
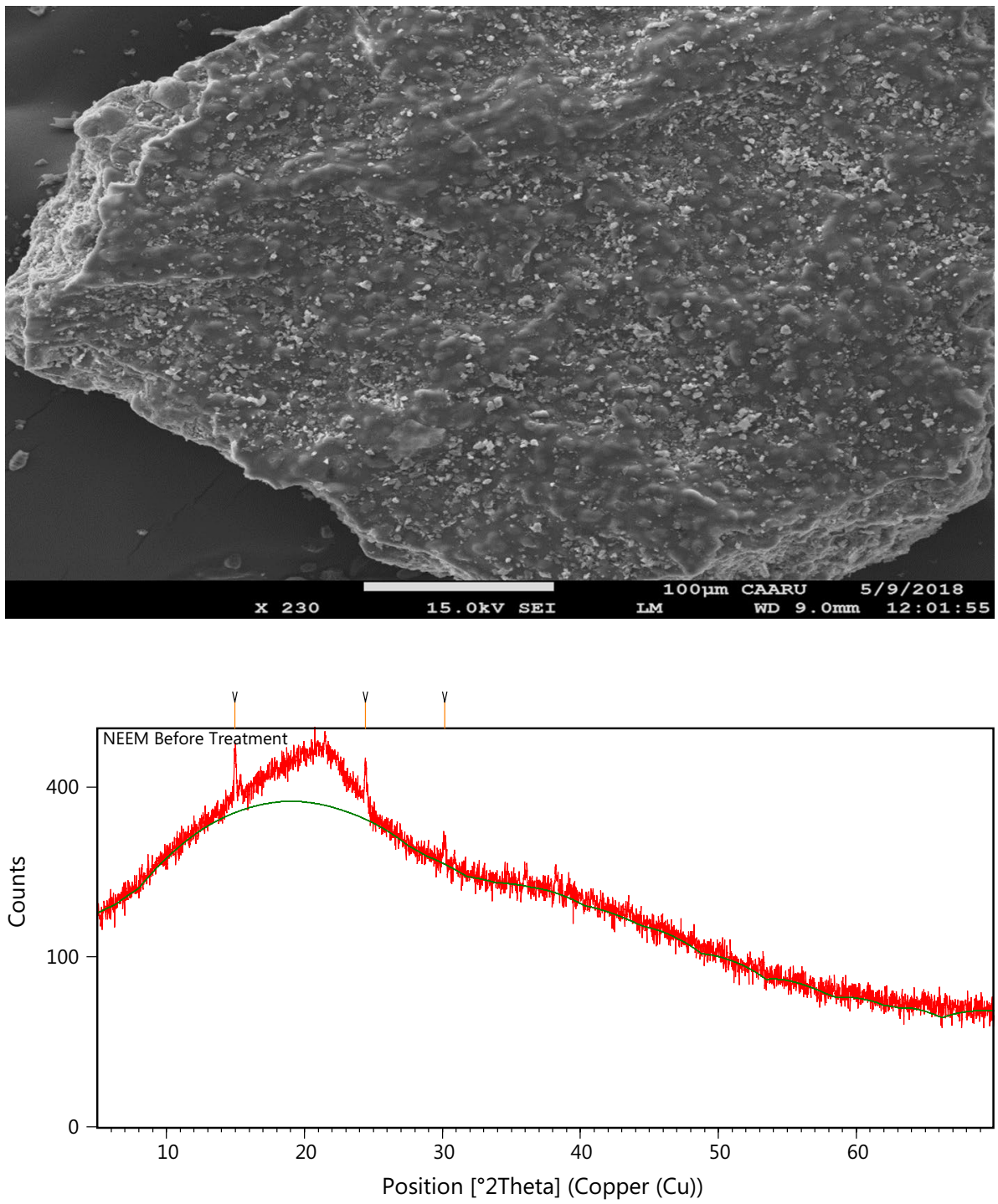
Fig. 3 FTIR spectra of activated Azadirachta indica powder sample before treatment

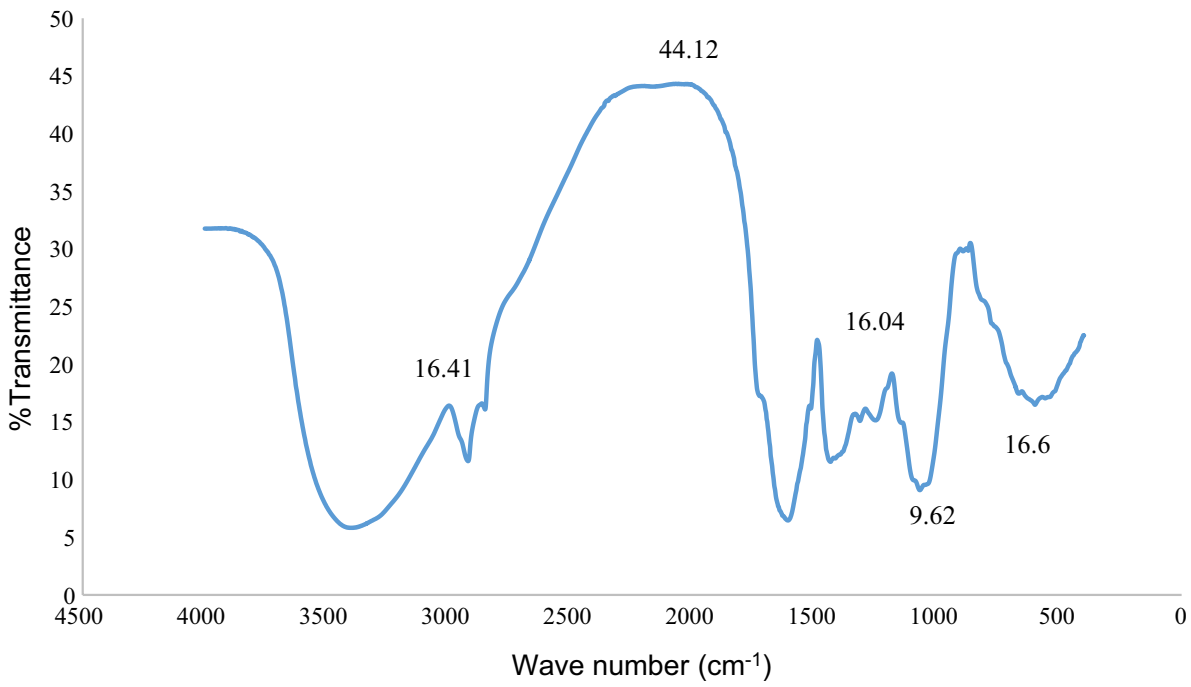

Table 1 Major functional groups present in the activated Azadirachta indica sample before treatment

\begin{tabular}{llll}
\hline \%Transmittance & $\begin{array}{l}\text { Wave number } \\
\left(\mathrm{cm}^{-1}\right)\end{array}$ & Classification & $\begin{array}{l}\text { Func- } \\
\text { tional } \\
\text { groups }\end{array}$ \\
\hline 16.41 & 3001 & Alkene & $\mathrm{C}-\mathrm{H}$ \\
44.12 & 2214 & Alkyne & $\mathrm{C} \equiv \mathrm{C}$ \\
9.62 & 1084 & Primary alcohol & $\mathrm{C}-\mathrm{O}$ \\
16.04 & 2987 & Alcohol & $\mathrm{N}-\mathrm{H}$ \\
16.6 & 2866 & Amine salt & $\mathrm{N}-\mathrm{H}$ \\
\hline
\end{tabular}

functional group and surface charge (Vijayaraghavan and Yun 2008).

\section{Biosorption studies}

\section{Influence of solution $\mathrm{pH}$}

The $\mathrm{pH}$ of the effluent solution is an important parameter contributing the metal adsorption, since $\mathrm{pH}$ is related to the ionization state of the particle surface, surface charge of adsorbent and type of adsorbate (Venkateswarlu et al. 2007; Sharma and Bhattacharyya 2004). The impact of variation of solution $\mathrm{pH}$ with percentage reduction of copper is shown in Fig. 4. As shown in Fig. 4, the percentage removal of copper ions increased to $58.8 \%$ with increase in $\mathrm{pH}$ up to 7.0 and above which there is a decreasing trend. Similar results have been reported in the literature (Mambo Moyo et al. 2016). Electrostatic interaction is the principal driving force for copper ion to adsorb on the surface of adsorbent. The greater the interaction, the higher is the adsorption of heavy metal. At low $\mathrm{pH}$, the hydrogen ions compete with copper ions for occupying suitable sites on the surface of adsorbent. The adsorption was significant at $\mathrm{pH} 7.0$, hydrogen ions become

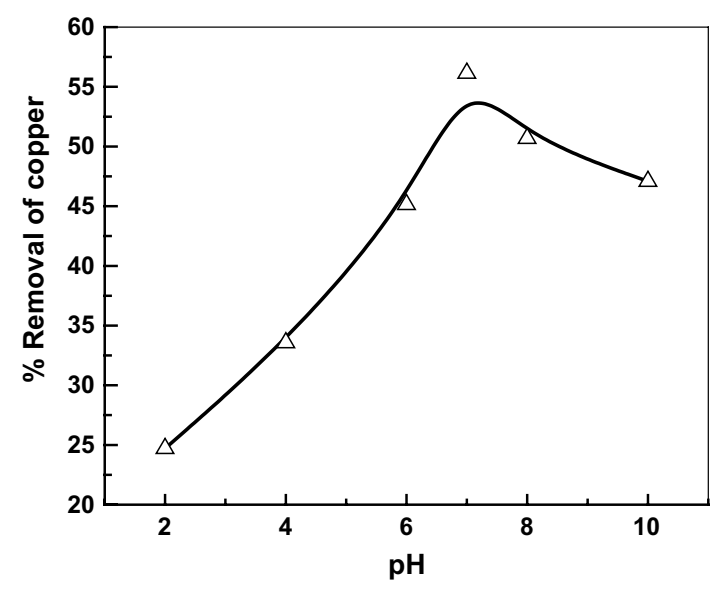

Fig. 4 Influence of solution $\mathrm{pH}$

negligible, and more copper ions will be deposited on the surface of adsorbent. The low removal efficiency is due to the decrease in surface charge, which will inhibit the metal uptake. The electrostatic repulsion between $\mathrm{Cu}$ (II) ion and available binding sites as well as the competing effect of protons decreased which proves to be more beneficial toward $\mathrm{Cu}(\mathrm{II})$ ions uptake. Above $\mathrm{pH}$ 7.0, adsorption of copper ions could not compete with $\mathrm{H}^{+}$ions for appropriate sites on the adsorbent surface.

\section{Influence of stirring time}

The mixing time at which adsorption equilibrium occurs is very important for the process optimization. The effect of variation of stirring time on the percentage removal of copper was studied by varying the contact time from 30 to $120 \mathrm{~min}$. It was observed that the increase in agitation time increases the percentage removal of copper. The maximum 
removal of copper was attained at a stirring time of $60 \mathrm{~min}$, and thereafter, it proceeds at a slower rate and finally no further significant adsorption. The adsorption was faster at the beginning and reached 59\% removal efficiency in the first $60 \mathrm{~min}$, and then, a decreasing trend is observed beyond $60 \mathrm{~min}$. The effect of variation of stirring time with \% reduction of copper is shown in Fig. 5.

The increase in adsorption rate is due to the attraction of copper ions toward active functional groups present on the adsorbent surface, which led to stronger surface binding. As the sites are completely occupied by the adsorbate, the adsorption is controlled by the rate at which the copper ions are transported from exterior to interior sites. Similar tendencies were reported in the literature (Chen et al. 2010; Ozer 2007). Therefore, 60 min was seen as sufficient for adsorption to attain equilibrium and was used in further experiments.

\section{Influence of stirring speed}

The influence of change in stirring speed on the percentage removal of copper was carried out by varying the speed from 25 to $150 \mathrm{RPM}$. The optimum percentage reduction was obtained when the stirring speed was 125 RPM, and almost complete removal of copper took place when the $\mathrm{pH}$ was 7.0 and the stirring was continued for $60 \mathrm{~min}$. The results indicate that an increase in stirring speed increased the percentage removal of copper for the range of 25-125 RPM. However, when the speed was increased beyond 125 RPM, there was a decreasing trend in the removal of copper as shown in Fig. 6.

\section{Influence of dosage}

Amount of biosorbent has a direct influence on the adsorption process. The biosorbent surface regulates the number of

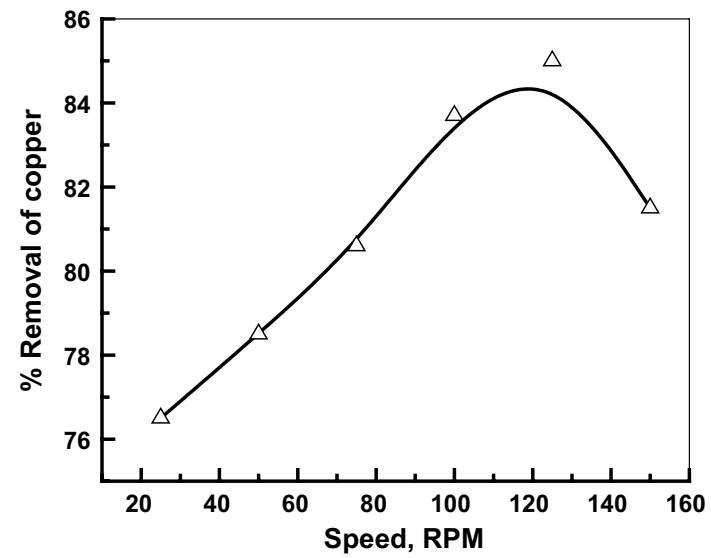

Fig. 6 Influence of stirring speed

binding sites available for adsorption at a specified solution concentration. The effect of variation of dosage of $A$. Indica powder on percentage removal of copper was monitored by changing the dosage from 0.2 to $1.6 \mathrm{~g}$, and the results are shown in Fig. 7.

The results indicate that the percentage reduction in efficiency increased with increase in biosorbent dosage up to $1.0 \mathrm{~g}$, above which there observed a declining trend. This is due to an increase in biosorbent dosage which could increase adsorption capacity due to the availability of more exchangeable active sites for copper ion adsorption. With increasing dosage, more surface area was available for biosorption due to the increase in active sites on the surface $A$. Indica and hence faster the adsorption rate. At equilibrium, the efficacy of copper removal decreased with increase in dosage of $A$. Indica from $1.0 \mathrm{~g}$. This decrease could be due to the concentration gradient and also due to the blockage of available active sites or groups. Similar results are found in previous studies (Rasheed et al. 2014). The amount of adsorbent

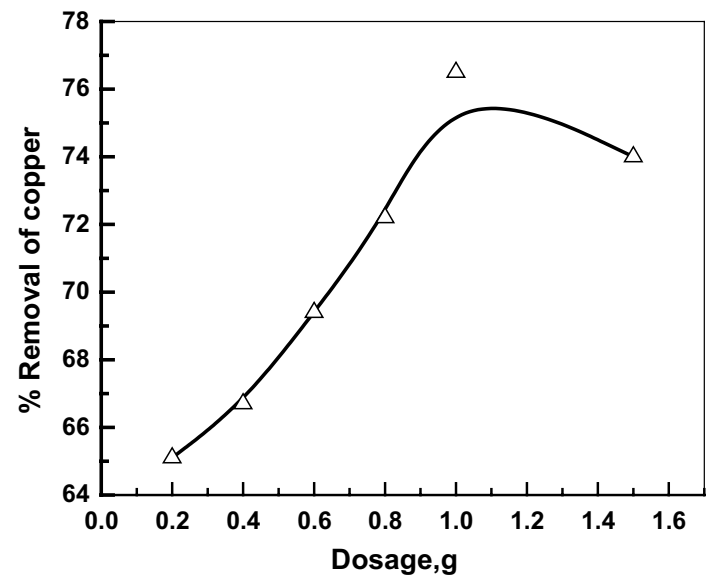

Fig. 7 Influence of biosorbent dosage
Fig. 5 Influence of contact time

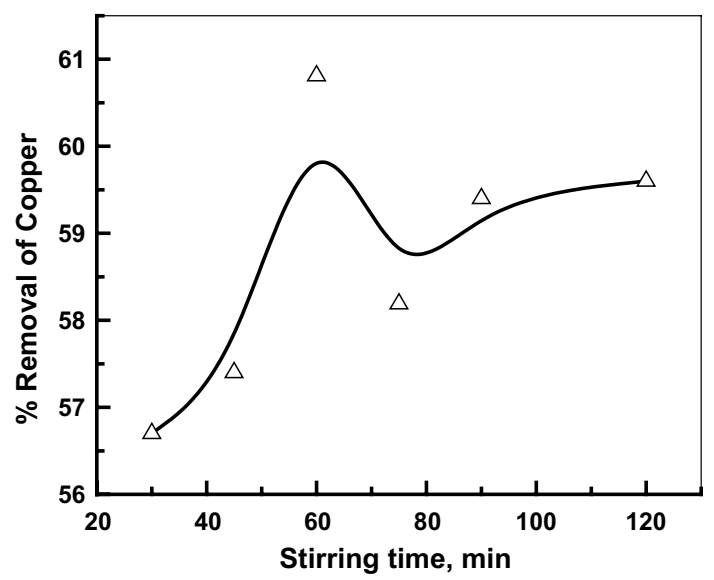

1

年

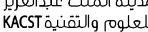


dosage above $1.0 \mathrm{~g}$ did not show a significant increase in the percentage removal. The probable reason might be due to the concentration of copper ions reaching equilibrium status between the solid and solution phase. Consequently, an adsorbent dosage of $1.0 \mathrm{~g}$ was chosen for further experiment. Effect of dosage of $A$. Indica was one of the determining factors contributing the removal efficiency. A decreasing trend in removal efficiency was observed when the dosage was above $1.0 \mathrm{~g}$.

\section{Influence of initial concentration}

The effect of variation of initial copper ion concentration was investigated for $0-120$ ppm as shown in Fig. 5. The study shows that the \% removal of copper increased with increase in concentration up to $110 \mathrm{ppm}$ and above which there is no more adsorption and reached a saturation limit. This may be due to an increase in the initial ion

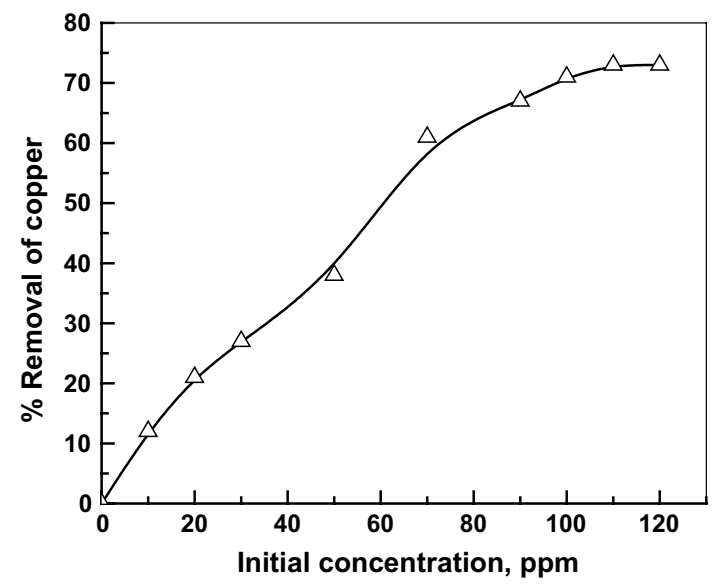

Fig. 8 Influence of solution concentration concentration providing a larger driving force to overcome all mass transfer resistances between the solid and the aqueous phase, thus resulting in higher copper ion adsorption at initial stages (Mambo Moyo et al. 2016). The maximum removal efficiency of copper was observed at $73 \%$. After $120 \mathrm{ppm}$, there is no further adsorption because of blocking of surface area of adsorbent. Figure 8 indicates that the metal sorption capacity increased with an increase in the initial copper ion concentration.

As the concentration of metal ions further increased, less active site will be available for accommodating excess amount of copper ions in solution. Subsequently, an initial concentration of $110 \mathrm{ppm}$ was used in all further studies.

The functional groups present in the A. Indica powder before and after copper ions adsorption are presented in Figs. 3 and 9. After the biosorption process, the positions of functional groups were shifted to new location and the details of the functional groups present are shown in Table 2. Figure 9 indicates FTIR spectra of $A$. Indica powder sample after treatment. It was observed from Fig. 9 that the amino and hydroxyl groups might be responsible for adsorption of copper ions. Similar results were

Table 2 FTIR spectra of Azadirachta indica powder after treatment

\begin{tabular}{llll}
\hline \% Transmittance & $\begin{array}{l}\text { Wave } \\
\text { number } \\
\left(\mathrm{cm}^{-1}\right)\end{array}$ & Class & Functional group \\
\hline 27.98 & 3450 & Alcohol & $\mathrm{O}-\mathrm{H}$ \\
42.12 & 2945 & Amine salt & $\mathrm{N}-\mathrm{H}$ \\
58.45 & 1831 & $\begin{array}{c}\text { Aromatic com- } \\
\text { pound }\end{array}$ & $\mathrm{C}-\mathrm{H}$ \\
57.73 & 842 & $\begin{array}{c}\text { Halocompound } \\
\text { Aldehyde }\end{array}$ & $\mathrm{C}-\mathrm{Cl}$ \\
50.04 & 2753 & $\mathrm{C}-\mathrm{H}$ \\
\hline
\end{tabular}

Fig. 9 FTIR spectra of Azadirachta indica powder sample after treatment. (Conditions: $\mathrm{pH} 7.0$, stirring time $=60 \mathrm{~min}$, dosage $=1.0 \mathrm{~g}$, stirring speed $=125 \mathrm{RPM}$ and concentration $=110 \mathrm{ppm}$ )

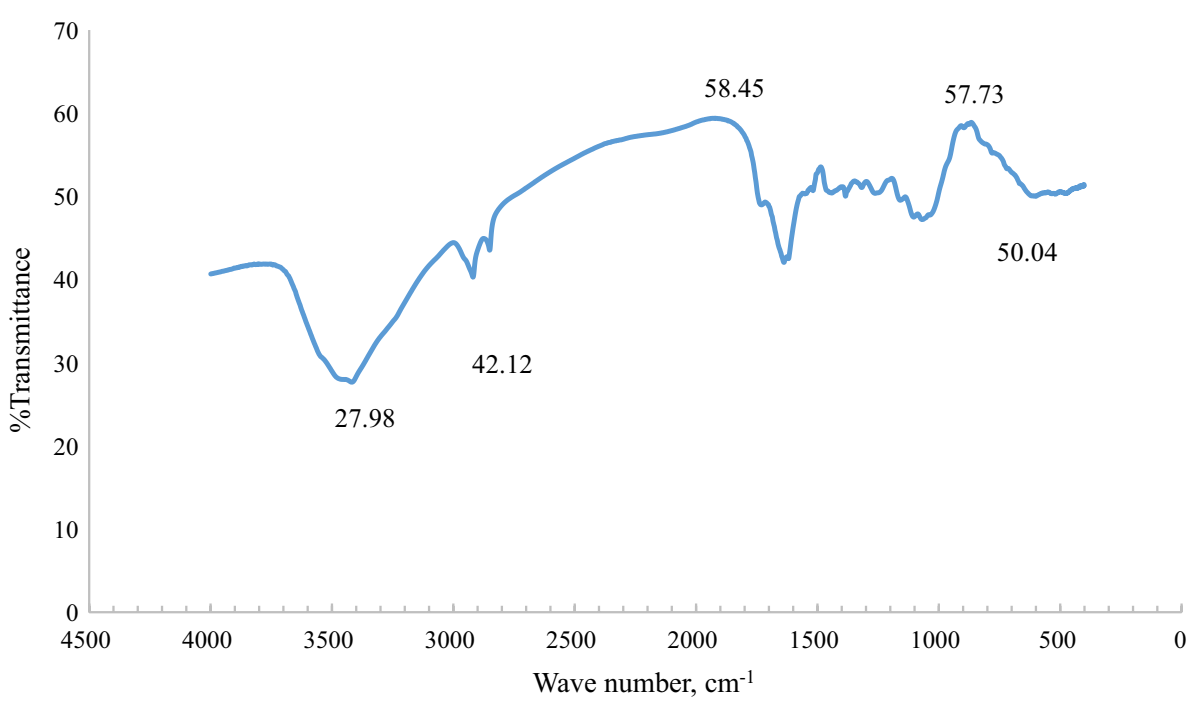


reported for copper ion adsorption using Cinnamomum camphora leaf powder (Chen et al. 2010; Ozer 2007).

Figure 10 indicates the surface morphology of $A$. Indica powder after biosorption. The SEM micrograph indicates that the surface of the biosorbent is covered with copper ions and the surface becomes very thick due to the deposition of copper ions, which indicates that the active sites present in the A. Indica powder play an important role in the adsorption process. The morphological characteristic shows the successful deposition of copper ions onto the surface of A. Indica powder. The SEM image shows the existence of copper on the surface in the form of bright spots, of which the distribution of copper is not uniform. This would indicate that some of the functional groups present on the surface of adsorbent were responsible for the uptake of copper from the bulk solution.
The phase identification of the sample was analyzed using X-ray diffractometer, and Figs. 2 and 11 indicate the XRD pattern of the sample before and after treatment.

\section{Conclusions}

Biosorbents are highly effective in the removal of heavy metal ions from wastewater at an affordable cost without any harmful effects on the environment and living organisms. The current study focused on the removal of copper ions present in the effluent using $A$. Indica powder, a natural biosorbent. The optimized processing conditions obtained are $7.0 \mathrm{pH}, 60 \mathrm{~min}$ of stirring time, $1.0 \mathrm{~g}$ dosage, $125 \mathrm{RPM}$ stirring speed and $110 \mathrm{ppm}$ of effluent concentration. The characterization of the adsorbent was performed using SEM, XRD and FTIR. The outcome of the research shows that $A$.
Fig. 10 SEM micrograph of Azadirachta indica powder after treatment at a magnification of $\times 430$ and an excitation voltage of $15.0 \mathrm{kV}$. (Conditions: $\mathrm{pH} 7.0$, stirring time $=60 \mathrm{~min}$, dosage $=1.0 \mathrm{~g}$, stirring speed $=125$ RPM and concentration $=110 \mathrm{ppm}$ )
Fig. 11 XRD pattern of Azadirachta indica powder after treatment. (Conditions: $\mathrm{pH} 7.0$, stirring time $=60 \mathrm{~min}$, dosage $=1.0 \mathrm{~g}$, stirring speed $=125 \mathrm{RPM}$ and concentration $=110 \mathrm{ppm}$ )
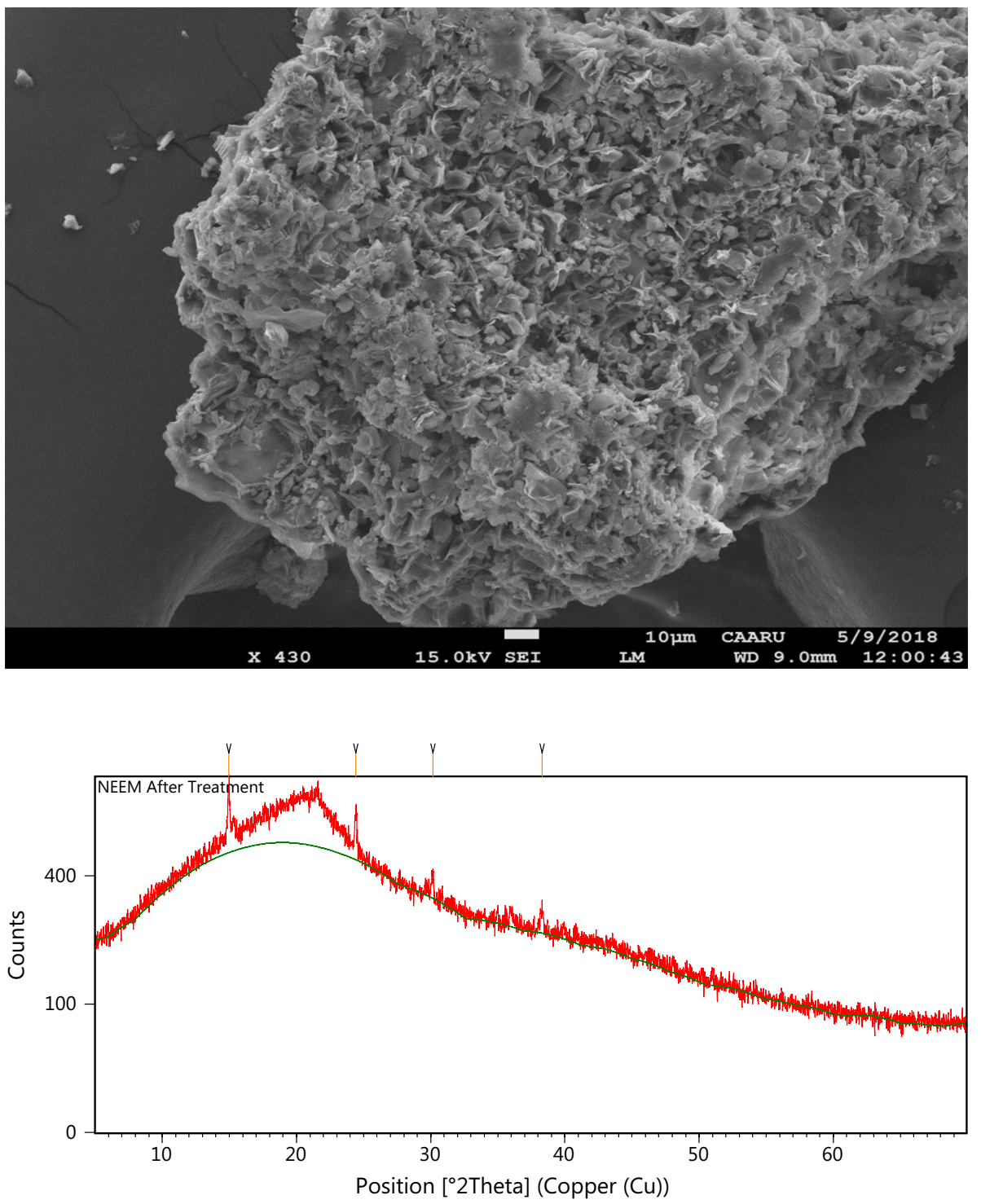
Indica powder is an economical, environmentally friendly and effective adsorbent in the removal of copper ions from industrial wastewater. The research team is currently working on the possibility of extending the study to other types of biosorbents such as microalgae for the effective removal of $\mathrm{Cu}, \mathrm{Ni}$ and $\mathrm{Cr}$ for comparison purpose.

Acknowledgements The authors greatly acknowledge National University of Science \& Technology - College of Engineering, for providing the infrastructural facilities.

\section{Compliance with ethical standards}

Conflict of interest The authors declare that there is no conflict of interest.

Open Access This article is distributed under the terms of the Creative Commons Attribution 4.0 International License (http://creativeco mmons.org/licenses/by/4.0/), which permits unrestricted use, distribution, and reproduction in any medium, provided you give appropriate credit to the original author(s) and the source, provide a link to the Creative Commons license, and indicate if changes were made.

\section{References}

Ang XW, Sethu VS, Andresen JM, Sivakumar M (2012) Copper(II) ion removal from aqueous solutions using biosorption technology: thermodynamic and SEM-EDX studies. Clean Technol Enviorn Policy 15:401-407

Arshad M, Zafar MN, Younnis S, Nadeem R (2008) The Use of neem biomass for the biosorption of zinc from aqueous solutions. J Hazard Mater 157:534-540

Basha S, Murthy ZVP, Jha B (2008) Biosorption of hexavalent chromium by chemically modified seaweed Cystoseira indica. Chem Eng J 137(3):480-488

Ceribasi IH, Yetis U (2001) Biosorption of $\mathrm{Ni}(\mathrm{II})$ and $\mathrm{Pb}$ (II) by Phanerochaete chrysosporium from a binary metal system-kinetics. Water SA 27(1):15-20

Chen H, Dai G, Zhao J, Zhong A, Wu J, Yan H (2010) Removal of copper(II) ions by a biosorbent Cinnamomum camphora leaves powder. J Hazard Mater 177:228-236

Davis TA, Volesky B, Mucci A (2003) A review of the biochemistry of heavy metal biosorption by brown algae. Water Re 37:4311-4330

El Nemr A (2007) Pomegranate husk as an adsorbent in the removal of toxic chromium from wastewater. Chem Ecol 23(5):409-425

Febriana N, Sisca OL, Felycia E, Soetaredjo JS, Ismadji S (2010) Neem leaf utilization for copper ions removal from aqueous solution. $\mathrm{J}$ Taiwan Inst Chem Eng 41:111-114

Islamuddin, Gautam RK, Siddique NF, More N (2016) Azadirachta Indica (neem) leaf powder used as a natural adsorbent for the removal of chromium $\mathrm{Cr}(\mathrm{VI})$ from an aqueous solutions. Int Res J Eng Technol 3(8):2234-2239

Kumar PA, Ray M, Chakraborty S (2007) Hexavalent chromium removal from wastewater using aniline formaldehyde condensate coated silica gel. J Hazard Mater 143(1-2):24-32
Li Y, Gao B, Wu T, Sun D, Li X, Wang B, Lu F (2009) Hexavalent chromium removal from aqueous solution by adsorption on aluminum magnesium mixed hydroxide. Water Res 43(12):3067-3075

Malairajan S, Alemayehu A, Vinodhini S (2007) Studies on the removal of hexavalent chromium from industrial waste water by using biomass. Electron J Environ Agric Food Chem 6(11):2557-2564

Malik R, Lata S, Singhal S (2014) Neem leaf utilization for copper and zinc ions removal from aqueous solution. Int J Sci Res 3(5):695-705

Manjunatha KR, Vagish M (2016) Study on adsorption efficiency of neem leaves powder in removal of reactive red dye color from aqueous solution. Int Res J Eng Technol 3(7):437-440

Moyo M, Chirinda A, Nharingo T (2016) Removal of copper from aqueous solution using chemically treated potato (Solanum tuberosum) leaf powder. CLEAN Soil Air Water 44(5):488-495

Muhammad BI, Muhammad SS, Sani S (2015) Assessment of adsorption properties of neem leaves wastes for the removal of congo red and methyl orange. In: 3rd International conference on biological, chemical \& environmental sciences (BCES-2015) Sept 21-22, Kuala Lumpur

Ozer A (2007) Removal of $\mathrm{Pb}$ (II) ions from aqueous solutions by sulphuric acid-treated wheat bran. J Hazard Mater 141(3):753-761

Pandhare G, Trivedi N, Kanse N, Dawande SD (2013) Synthesis of low cost adsorbent from Azadirachta indica (neem) leaf powder. Int J Adv Eng Res Stud II(II):29-31

Paulino AT, Minasse FAS, Guilherme MR, Reis AV, Muniz EC, Nozaki J (2006) Novel adsorbent based on silkworm chrysalides for removal of heavy metals from wastewaters. J Colloid Interface Sci 301:479-487

Pournima RP, Shrikant MB (2018) Experimental dose optimization for $\mathrm{Cu}$ removal from water using neem leaves. Int J Curr Eng Technol 8(5):1329-1332

Puziah AL, Chin TS (2007) Removal of chromium(III) from aqueous solution and industrial wastewater using natural rice husk and fly ash as adsorbents. ICFAI J Environ Sci 1(2):68-80

Rasheed AA, Sethu V, Jewaratnam J (2014) Biosorption of Cu(II) ions from aqueous solutions using neem (Azadirachta indica) leaf powder: biosorbent dosage and $\mathrm{pH}$ effects. In: Proceeding the regional conference of chemical engineering

Sethu V, Andresen J, Cloke M (2009) Biosorption of Cu(II) from wastewater using Azadirachta indica (neem leaves). J Environ Res Dev 3(3):614-620

Sharma A, Bhattacharyya KG (2004) Adsorption of chromium(VI) on Azadirachta indica (neem) leaf powder. Adsorption 10(4):327-338

Sulaiman MS, Garba MD (2014) Biosorption of $\mathrm{Cu}(\mathrm{II})$ ions from aqueous solution using Azadirachta indica (neem) leaf powder 27. Chem Process Eng Res 4(3):139-231

Suresh G, Babu BV (2006) Adsorption of chromium(VI) by a low-cost adsorbent prepared from tamarind seeds. In: National conference on environmental conservation (NCEC-2006). Birla Institute of Technology and Science

Venkateswarlu P, Ratnam MV, Rao DS, Rao MV (2007) Removal of chromium from an aqueous solution using Azadirachta indica (neem) leaf powder as an adsorbent. Int J Phys Sci 2(8):188-195

Vijayaraghavan K, Yun YS (2008) Bacterial biosorbents and biosorption. Biotechnol Adv 26:266-291

Volesky B (2001) Detoxification of metal-bearing effluents: biosorption for the next century. Hydrometallurgy 59:203-216

Volesky B, Holan ZR (1995) Biosorption of heavy metals. Biotechnol Prog 11:235-250 
Zhonghua H, Lei L, Li Y, Ni Y (2003) Chromium adsorption on highperformance activated carbons from aqueous solution. Sep Purif Technol 31(1):13-18
Publisher's Note Springer Nature remains neutral with regard to jurisdictional claims in published maps and institutional affiliations. 